\title{
Surgical treatment of dyskinesia in Parkinson's disease
}

\author{
Renato P. Munhoz ${ }^{1}{ }^{*}$, Antonio Cerasa ${ }^{2,3}$ and Michael S. Okun ${ }^{4}$ \\ 1 Division of Neurology, Department of Medicine, University of Toronto, Toronto Western Hospital, Toronto, ON, Canada \\ ${ }^{2}$ Neuroimaging Unit, Institute of Molecular Bioimaging and Physiology, National Research Council (IBFM-CNR), Germaneto, Italy \\ ${ }^{3}$ Magna Græcia University of Catanzaro, Germaneto, Italy \\ ${ }^{4}$ Department of Neurology, McKnight Brain Institute, University of Florida College of Medicine, Gainesville, FL, USA
}

\section{Edited by:}

Alfonso Fasano, Catholic

University - A. Gemelli Hospital, Italy

\section{Reviewed by:}

Francesca Morgante, University of

Messina, Italy

Maria Stamelou, University of

Athens, Greece

${ }^{*}$ Correspondence:

Renato P. Munhoz, Division of Neurology, Department of Medicine,

University of Toronto, Toronto Western Hospital, McLaughlin Pavilion 7th

Floor Room 7-417, 399 Bathurst

Street, Toronto, M5T 2S8 ON, Canada

e-mail: renato.munhoz@uhn.ca
One of the main indications for stereotactic surgery in Parkinson's disease (PD) is the control of levodopa-induced dyskinesia. This can be achieved by pallidotomy and globus pallidus internus (GPi) deep brain stimulation (DBS) or by subthalamotomy and subthalamic nucleus (STN) DBS, which usually allow for a cut down in the dosage of levodopa. DBS has assumed a pivotal role in stereotactic surgical treatment of PD and, in fact, ablative procedures are currently considered surrogates, particularly when bilateral procedures are required, as DBS does not produce a brain lesion and the stimulator can be programed to induce better therapeutic effects while minimizing adverse effects. Interventions in either the STN and the GPi seem to be similar in controlling most of the other motor aspects of PD, nonetheless, GPi surgery seems to induce a more particular and direct effect on dyskinesia, while the anti-dyskinetic effect of STN interventions is mostly dependent on a reduction of dopaminergic drug dosages. Hence, the si ne qua non-condition for a reduction of dyskinesia when STN interventions are intended is their ability to allow for a reduction of levodopa dosage. Pallidal surgery is indicated when dyskinesia is a dose-limiting factor for maintaining or introducing higher adequate levels of dopaminergic therapy. Also medications used for the treatment of PD may be useful for the improvement of several non-motor aspects of the disease, including sleep, psychiatric, and cognitive domains, therefore, dose reduction of medication withdrawal are not always a fruitful objective.

Keywords: Parkinson's disease, dyskinesia, deep brain stimulation, DBS, pallidotomy

\section{INTRODUCTION}

Treatment of levodopa-induced dyskinesia (LID) is one of the most common indications for stereotactic surgery in Parkinson's disease (PD). Control of LID can be accomplished by providing significant relief on the motor symptoms of PD through medication optimization, typically through subthalamic nucleus (STN) deep brain stimulation (DBS), or by pallidotomy or globus pallidus internus (GPi) DBS, which are thought to have a direct effect on dyskinesia (1). Currently, DBS has become the preferred stereotactic procedure in $\mathrm{PD}$, however, ablative surgery continues to be performed and can be quite effective especially when dyskinesia are significantly more prominent on one body side. In this review, we will address both forms of surgical techniques, their indications, differentials, and outcomes.

\section{ABLATIVE SURGERY}

The indication for any form of stereotactic ablative surgery has always been the symptomatic treatment of certain motor features of PD as identified during a detailed multi-disciplinary workup. As early as the 50s, the inner segment of the GPi and the ansa lenticularis has been the common choice for functional neurosurgeons (2). This approach was advocated and further reinforced following the observation that ligation of the anterior choroidal artery, performed for the treatment of accidental bleeding in a PD patient, resulted in relief of tremor $(3,4)$. As this technique (ansa - pallidotomy) became more widely utilized, the results for tremor control were mixed, despite the good outcome for rigidity. As a result, pallidotomy was gradually replaced by thalamotomy, which exerted a more optimal tremor control (5). The failure to reduce tremor in some cases was likely due to a failure to target the appropriate postero-ventral pallidum, which was a limitation of early technology. However, with the advent of levodopa in the 1960s, stereotactic surgery became gradually less popular and did not re-emerge again until the early 90 s (6).

The renaissance of stereotactic surgery for patients with PD was galvanized by the weaknesses of levodopa therapy that were gradually surfacing (7). The first disappointment was the evidence that it does not interfere positively with disease progression, as it is now well appreciated after decades of use. Additionally, due to the high doses sometimes required to improve tremor, motor fluctuations, and LID started to be noticed. As most clinicians continue to witness today, medical pharmacological management of PD is challenging with the continuous attempt to balance the relief of parkinsonian motor signs against motor fluctuations and induction of dyskinesia, often with neither being managed adequately (8). The setback related to levodopa was allied with advancements from physiological and surgical aspects, and also by the more accurate understanding of the organization of the basal ganglia (BG), better surgical techniques, and the use of neuroimaging for more precise target localization. At that time, thalamotomy was revived, and, in addition to improvements in the motor aspects of PD, several authors reported drastic suppression of LID (9). 
Svennilson et al. reported that when the postero-ventral GPi was lesioned additional benefit to general motor function (interpreted as corresponding to relief of akinesia) could be obtained (10). Later, Laitinen et al. returned to the initial target and the postero-ventral GPi became the preferred surgical treatment for PD patients. In the classical report from 1992, Laitinen's group showed favorable outcomes that included not only robust improvements in the cardinal signs of PD, but also significant amelioration of LID (11).

At approximately the same time, anatomic and physiological studies confirmed that the GPi and STN were both overactive in PD. Also, experimental studies demonstrated that lesions in these structures could improve parkinsonism and dyskinesia in animal models (12-14), although the classical BG model predicted that pallidotomy would worsen dyskinesia. This discrepancy between theoretical and practical outcomes is probably the result of interference with abnormal firing patterns (rather than rates) in circuit neurons (15).

Both the clinical report by Laitinen et al. and the pathophysiological laboratory-based developments in PD reinforced the role of pallidotomy for treatment of LID in PD.

\section{PALLIDOTOMY}

During the second half of the 90s, many studies reported that unilateral pallidotomy in patients with PD provided successful control of contralateral dyskinesia. At that time, Lozano et al. (15) published the results of pallidotomy in 14 patients with rigid akinetic PD, complicated by severe LID, motor fluctuations, but with intact cognition. Motor improvements in the OFF medication condition were mainly contralateral. The most dramatic improvement was for ON period LID, which were shown to be reduced by $92 \%$ in the contralateral side after 6 months. The typical complications of this procedure, homonymous hemianopia, facial paresis, and hemiparesis, were not observed, except for mild and transient facial droop in three cases (noted by clinicians but not the patients). Two years later, the same group published a series of 40 cases, some with a longer follow-up: 27 for 1 year and 11 for 2 years. Short term results were similar to their previous study, however trend analysis revealed a slight worsening of contralateral dyskinesia after the first year, and a loss of benefit for ipsilateral dyskinesia by the second year. Age had an impact on OFF period motor signs, with those older than 65 retaining less improvement after 6 months. LID responded similarly in the two age groups studied. There were no significant reductions in dopaminergic therapy after surgery. Persistent adverse events included facial weakness (two cases), bulbar deficits (three cases), mild dementia (three cases), and worsening of handwriting in four cases (16). The findings in the same cohort were also described after a much longer followup (mean 52 months), showing a sustained improvement in OFF period contralateral motor signs and in LID. Other than dyskinesia and levodopa responsive motor signs, no additional characteristics had a significant impact on long-term surgical outcome (17).

In 1998, another group published a preliminary study with a series of $26 \mathrm{PD}$ patients, confirming that the most significant effect following unilateral ventral medial pallidotomy was the reduction of contralateral LID by $67 \%$, while ipsilateral and axial dyskinesia also improved (both around 50\%) significantly. The improvement in underlying parkinsonism as measured by comparing the Unified Parkinson's Disease Rating Scale (UPDRS) scores in the OFF state before and 3 months after surgery, was less robust (27\%). On medication, no significant post-operative improvements in parkinsonism were detected and antiparkinsonian medication dosages increased by $11 \%$ post-operatively. The presence of disabling LID, therefore, was considered the major indication for this surgical procedure. Two (7.7\%) patients died due to cerebral hemorrhages directly related to surgery, while another $15 \%$ had major complications (significant focal motor and bulbar deficits) (18). In 2003, the first randomized, prospective controlled trial comparing pallidotomy with best medical therapy was published. The study included 18 patients in each group, showing, after 6 months, a $32 \%$ improvement of the total UPDRS motor score in the surgical group versus only a $5 \%$ deterioration for those randomized for medical therapy. Mean score improvement in the dyskinesia section of the UPDRS (Part IV) for the surgical group was $45 \%$, whereas patients kept on medical therapy worsened by $8 \%$. The study also revealed that LID improved after pallidotomy in all patients, and two-thirds had "complete relief" on the contralateral side. Also, there was a 36\% reduction in ipsilateral dyskinesia severity. Levodopa equivalent doses remained unchanged. There were no fatal outcomes and complications occurred in three cases $(16.7 \%)$. This study also showed that the age had a clear relationship with clinical outcome, independent of disease duration, with younger patients showing more improvement. This effect was continuous, with no apparent threshold (19).

The series with the longest follow-up was by Kleiner-Fisman et al. and included 10 patients, showing a trend toward significance lasting up to 12 years in contralateral LID (20), and by Hariz and Bergenheim who reviewed 13 of the 38 patients described in Laitinen's original study from 1992. Mean follow-up was 10.5 years (up to 13.5), and the effect of surgery remained consistent for contralateral LID, but varied for the appendicular OFF period signs. The authors went as far as to consider pallidotomy as a prophylactic measure against LID (21).

Lesion size does not seem to have a significant effect on response (22), however, the optimal location within the GPi that improved dyskinesia is a matter of controversy. Lesion location and size may be different from that required to ameliorate other PD signs, and some experts still advocate a bigger lesion size for prolonged benefit. While anteromedially placed lesions seems to be better correlated with improvement in contralateral LID, central and posterolateral placed lesions improved OFF parkinsonian signs (23). However, lesions placed in more ventral locations or anywhere in the postero-ventral GPi have been shown to be equally effective (16). Differences in outcome measures as well as in methods of determining lesion location probably account for many of these discrepancies.

Bilateral pallidotomies, staged and simultaneous, produce similar improvements in OFF motor and ON dyskinesia to unilateral procedures, with the possible advantage of improvements in axial dyskinesia, dystonia, and, arguably, selected aspects of gait such as walking speed and freezing $(24,25)$. These good results were undermined by unacceptable cognitive and bulbar (mainly speech) adverse effects (26). Only a few other studies have shown different perspectives $(27,28)$. The series by Parkin et al. (29) 
Table 1 | Patient selection and point to be considered when indicating stereotactic surgery for dyskinesias in Parkinson's disease.

\begin{tabular}{|c|c|c|c|c|}
\hline & Advantages & Disadvantages & Patient profile & Post-operative details \\
\hline $\begin{array}{l}\text { Unilateral } \\
\text { pallidotomy }\end{array}$ & $\begin{array}{l}\text { Efficacious } \\
\text { Less costly than DBS } \\
\text { Does not require post-operative } \\
\text { programming } \\
\text { No complications related to } \\
\text { hardware (infections, malfunction) }\end{array}$ & $\begin{array}{l}\text { Permanent lesion } \\
\text { Not reversible } \\
\text { Bilateral surgery has higher risk } \\
\text { of side effects } \\
\text { Does not allow adjustments to } \\
\text { control side effects }\end{array}$ & $\begin{array}{l}\text { Unable to travel } \\
\text { Live where DBS is too expensive or } \\
\text { not available } \\
\text { Prefer not to have chronic hardware } \\
\text { High infection risk }\end{array}$ & $\begin{array}{l}\text { Ipsilateral dyskinesias may } \\
\text { not improve significantly, } \\
\text { requiring continuing } \\
\text { anti-dyskinetic medical } \\
\text { treatment or contralateral } \\
\text { GPi DBS }\end{array}$ \\
\hline GPi DBS & $\begin{array}{l}\text { Direct improvement in } \\
\text { dyskinesias } \\
\text { Allows adjustments in drug } \\
\text { regimen } \\
\text { May allow for maintaining or } \\
\text { introducing higher levels of } \\
\text { dopaminergic therapy } \\
\text { Synergistic effect with I-DOPA on } \\
\text { axial and other symptoms }\end{array}$ & $\begin{array}{l}\text { No significant change in drug } \\
\text { regimen in many but not all } \\
\text { cases } \\
\text { Ventral and dorsal stimulation } \\
\text { may induce opposite effects on } \\
\text { cardinal motor signs of PD } \\
\text { however this has not been } \\
\text { replicable on all cases }\end{array}$ & $\begin{array}{l}\text { Needs prompt improvement of } \\
\text { severe dyskinesias } \\
\text { Responds to low dose I-DOPA, but } \\
\text { has low threshold for dyskinesias } \\
\text { Has I-DOPA responsive non-motor } \\
\text { signs } \\
\text { In the right context, may be safer } \\
\text { for patients with mild pre-existing } \\
\text { cognitive symptoms }\end{array}$ & $\begin{array}{l}\text { Ensure that the beneficial } \\
\text { effect of I-DOPA is not } \\
\text { antagonized by stimulation }\end{array}$ \\
\hline STN DBS & $\begin{array}{l}\text { Allows significant reduction in } \\
\text { dopaminergic drug dosages } \\
\text { Effective for OFF period dystonia }\end{array}$ & $\begin{array}{l}\text { Improvements in dyskinesias } \\
\text { depend on reduction of levodopa } \\
\text { May have negative impact on } \\
\text { cognition } \\
\text { More laborious post-operative } \\
\text { management } \\
\text { May worsen or not improve } \\
\text { dyskinesia in brittle dyskinetics }\end{array}$ & $\begin{array}{l}\text { Has severe motor fluctuations } \\
\text { Uses higher doses of I-DOPA } \\
\text { Experiences disabling side effect of } \\
\text { dopaminergic treatment } \\
\text { Intact cognition }\end{array}$ & $\begin{array}{l}\text { Stimulation induced } \\
\text { dyskinesias may appear } \\
\text { after a latency of several } \\
\text { hours if I-DOPA not adjusted } \\
\text { The electrode that induces } \\
\text { dyskinesias is usually the } \\
\text { most effective }\end{array}$ \\
\hline
\end{tabular}

for instance, showed the results in 115 patients who underwent pallidotomy, 53 of which consisted of bilateral procedures. These authors reported significant effectiveness for bilateral pallidotomy, especially for dyskinesia for up to 12 months, at the expense of worsening of speech in $8 \%$ and salivation in $13 \%$, figures that were similar to those found for unilateral surgery. Table 1 shows a summary of the advantages, disadvantages, and other aspects to be considered when a pallidotomy is indicated.

\section{STUDIES COMPARING PALLIDOTOMY AND DEEP BRAIN STIMULATION OF THE GPi OR STN}

Few studies have compared the efficacy and safety of pallidotomy and DBS of the GPi or STN. Table 2 shows the results of the most important clinical parameters described in studies of pallidotomy and DBS techniques. An early, non-randomized trial comparing results of pallidotomy, STN, and GPi DBS concluded that GPi DBS had effects similar effects to pallidotomy, but is safer when bilateral procedures are required. Also, bilateral STN DBS may improve OFF period motor symptoms to a greater proportion than the other procedures, and might also improve ON period motor function (30). In 2004, Esselink et al. (31) compared, in a randomized, observer-blind trial, the effect of unilateral pallidotomy and bilateral STN DBS in patients with PD followed up for 6 months, confirming that stimulation was more effective in reducing OFF period motor signs. In addition, this procedure provided better ON period motor scores and a greater reduction of dopaminergic drug treatment dosages. Both improved LID and functional scales equally, and the number of adverse events was similar in both
Table 2 | Effects of unilateral pallidotomy, bilateral GPi and STN deep brain stimulation (DBS) on general motor improvement (UPDRS III), dyskinesias (UPDRS IV) and levodopa equivalent daily dose (LEDD).

\begin{tabular}{llll}
\hline & $\begin{array}{l}\text { Motor } \\
\text { improvement (\%) }\end{array}$ & $\begin{array}{l}\text { Improvement for } \\
\text { dyskinesias (\%) }\end{array}$ & $\begin{array}{l}\text { Reduction } \\
\text { in LEDD }\end{array}$ \\
\hline $\begin{array}{l}\text { Unilateral } \\
\text { pallidotomy }\end{array}$ & $25-45$ & $45-86$ & n.s. $(0-10 \%)$ \\
GPi DBS & $26-43$ & $47-88$ & n.s. $(15-17 \%)$ \\
STN DBS & $25-54$ & $20-83$ & $31-47 \%$
\end{tabular}

Mean improvement after a minimum of 6 months compared to preoperative baseline. Scores reflect the medication off condition; for DBS, stimulation on. n.s., non-significant (17, 32-41).

groups. The same group also published the results after 4 years with similar findings, except for dopaminergic treatment dosage, which did not significantly differ between groups after the first 12 months (32).

\section{DEEP BRAIN STIMULATION}

After DBS was introduced as a treatment option for movement disorders in general, this technique has slowly taken over a pivotal central role in stereotactic surgery. As a matter of fact, ablative procedures are currently regarded as alternatives, only used when DBS is not viable due to technical, travel, patient preference, and economic reasons $(42,43)$. 
Two of the reasons that favor DBS, particularly if bilateral procedures are required, are the facts that it is not intended to produce a brain lesion, and that the stimulator can be programed with respect to several variables, including electrode location, amplitude, frequency, and pulse width, to induce better therapeutic effects while minimizing adverse effects. In the case of PD, DBS electrodes have been placed in two main BG targets: the GPi, and the STN, though other targets are also possible (44).

\section{GPi DBS}

The first study to report results of this procedure described three patients in 1994, with the post-operative results described as "excellent," reflecting improvements in all motor signs of the disease, as well as for motor fluctuations and LID (45). During the following decade, descriptions of larger series confirmed these findings. A study with a follow-up of at least 24 months showed that the mean improvements in the UPDRS motor and activities of daily living scores after 12 months were more than $50 \%$, motor fluctuations were reduced from 40 to $10 \%$, and the score for LID was reduced to one third. Doses of levodopa tended to remain unchanged. Half of the patients experienced a slight worsening of levodopa and stimulation resistant gait and bulbar symptoms following 12 months (46). In 2000, a study by Kumar et al. (34) showed the results seen on a cohort of 22 consecutive cases of PD treated with GPi DBS, 17 of whom had bilateral surgeries. Post-operatively, at 6 months, the motor improvement in the OFF condition reached 31 and $66 \%$ reduction in LID.

The first double-blind, crossover study evaluating the results of GPi and STN DBS in PD was performed in 2001, showing that both procedures induced significant improvements in motor function and dyskinesia (by 58\% for STN and $66 \%$ for GPi DBS), however, the average medication used, measured in levodopa equivalents, decreased significantly more for the STN DBS patients (35). A study with longer follow-up, mean 48.5 months, showed a $64 \%$ mean improvement in dyskinesia after this period (36). Finally, another study followed up 11 patients with PD who underwent GPi DBS for up to 5 years, showing that, despite a decline on the motor benefit for the OFF period scores after 3 years, the improvement in LID was sustained for up to 5 years (47).

\section{STN DBS}

STN DBS for advanced PD was first introduced in the 1990s and is currently the most common form of a surgical treatment applied for this disorder worldwide. The initial series reported significant improvements in OFF period tremor, rigidity, and bradykinesia, as well as attenuation of motor fluctuations and LID, associated with a $50 \%$ reduction in dopaminergic treatment dosages (48). Subsequent studies confirmed these findings. In 2001, a prospective study of 91 patients showed, after 6 months, a robust improvement in all motor signs in the OFF condition, in the percentage of time with good mobility and no dyskinesia, mean dyskinesia score, as well as a mean reduction in daily levodopa dose equivalents (approximately 60\%) (35). At this point, it became clear that the reduction in dyskinesia could be attributed at least in part to the reduction of levodopa dosage. However, a few studies showed that this may not be the only element in this beneficial effect. A study designed to assess the effect of STN DBS on OFF period dystonia, and on diphasic and peak dose dyskinesia after a levodopa challenge using the same suprathreshold dose as before surgery with the stimulation on, showed a reduction of OFF period dystonia by $90 \%$, and of diphasic dyskinesia by $50 \%$, and of peak dose dyskinesia by $30 \%$ (49). The same authors had already reported that chronic STN DBS per se tends to reduce dyskinesia, as opposed to chronic activation of the dopaminergic system with levodopa. The authors speculated that this difference may have been due to the pulsatile nature of levodopa stimulation versus the more continuous activation provided by chronic STN DBS (50). There was also an important study by Oyama et al. that elegantly showed that dyskinesia could possibly be reduced in both the STN and GPi target. The authors accounted for medication reduction, and showed that in both targets there was a possibility of dyskinesia suppression without medication reduction (51).

Long-term studies of bilateral STN DBS in patients with advanced PD have demonstrated the stability of this therapy over time. A 5-year prospective study of 49 consecutive patients treated with STN DBS noted that OFF medication motor scores at 5 years were still $54 \%$ better than baseline (37). Worsening of ON medication akinesia, speech, postural stability, and freezing of gait was interpreted to be consistent with the natural progression of PD. However, LID benefits persisted, with dyskinesia disability and duration at 5 years being improved by 58 and $71 \%$, respectively in comparison with baseline. Similar benefits with respect to dyskinesia were observed in 37 patients followed for 5 years after DBS surgery (52). Finally, a comprehensive meta-analysis of 921 patients who underwent STN DBS between 1993 and 2004 noted an average reduction in LID of $69.1 \%$ (53).

\section{MECHANISMS OF ACTION IN REDUCING LEVODOPA-INDUCED DYSKINESIA Pallidal stimulation}

Restoration of the thalamocortical activity by suppression of the inhibitory output from the pallidum to the ventrolateral thalamus is the suspected mechanism for motor improvement underpinning GPi DBS, however, the cellular mechanisms of high-frequency stimulation are still unknown. The mechanism of GPi DBS in reducing dyskinesia is also not completely understood. The current views of the BG physiology suggest that inhibition of ventral GPi activity should induce dyskinesia, however, lesioning of the ventral pallidum provides relief of dyskinesia (54). One of the possible justifications for this apparent paradoxical response is that LID may be more correlated with an abnormal pattern than with the direction and intensity of the neuronal activity within the GPi $(54,55)$. Surgical modification of this patterned activity might be accomplished by lesioning (direct neuronal inhibition) or with DBS (indirect inhibition through activation of inhibitory axons close to the electrode). Dyskinesia might also arise from an abnormal balance of activity within different functional zones of the nucleus (ventral versus dorsal GPi) and stimulation may suppress this abnormal activity $(56,57)$. Finally, the anti-dyskinetic effect of GPi DBS maybe mediated through effects on the subthalamopallidal tract, which projects to the dorsal GP externus and GPi. Dorsal GPi stimulation might inhibit this projection and would be expected to improve PD symptoms and induce dyskinesia (58). 


\section{STN stimulation}

STN DBS mimics the effects of levodopa on parkinsonian motor symptoms and allows reduction of dopaminergic medication, secondarily relieving dyskinesia as medications are reduced or withdrawn post-operatively (51). However, improvement of dyskinesia is also sometimes observed in the early post-operative period after implantation of electrodes in the STN, even in the absence of a reduction of medications (1). This indicates a direct antidyskinetic effect of manipulation of the STN (or the vicinity of its dorsal border and perhaps the zona incerta), but long-term relief of dyskinesia generally requires reduction of medications. The specific site of action in stimulation of the STN is unknown. Some data indicate that the best effect can be achieved at the lowest intensity not through stimulation of neurons within the STN, but by stimulation of tissue dorsal to it, which might affect the pallidothalamic bundle, the pallidosubthalamic tract, and/or the zona incerta (59). Other data indicate that the most effective contact location appears to be within the anterodorsal portion of the STN, although current could spread from this location into the directly superior fields of Forel and zona incerta (60). The observation that an active DBS contact dorsal to the STN may provide better control of dyskinesia (indicative of a direct anti-dyskinetic effect) supports the notion that activation of structures dorsal to the STN is important in providing relief of parkinsonian symptoms by DBS of the STN (38). Overall, the specific mechanisms of action of GPi and STN DBS in suppressing dyskinesia are unknown.

\section{STUDIES COMPARING THE EFFECT OF GPi AND STN DBS}

A few studies have compared the effect of GPi and STN DBS on PD. Table 2 shows the results of the most important clinical parameters described in studies comparing these two techniques. The first study to do that was published in 2001, it had a relatively short follow-up period after surgery ( 3 months), and revealed similar improvements in OFF period motor parameters, as well as for ON dyskinesia, with the caveat that only the STN group was able to significantly reduce the levodopa equivalent dose (35). In 2005, a non-randomized extension of this study with 105 patients followed up for at least 3 years, showed that, in addition to improvements in all motor signs of parkinsonism in the OFF condition, STN DBS significantly improved OFF dystonia and ON dyskinesia, while GPi had a similar effect on ON dyskinesia with no significant improvement on OFF dystonia. In this study, reduction in post-operative levodopa equivalent doses was significant only for the STN group, in which more than $10 \%$ of patients stopped taking levodopa. These changes were sustained after up to 4 years of follow-up (36). Moro et al., in an double-blind, nonrandomized study with 35 patients who underwent STN DBS and 16 who underwent GPi DBS, found that both procedures induced significant improvements in OFF period motor signs, ADLs, and ON dyskinesia scores, although only the STN group had a significant reduction in the doses of levodopa. These results were sustained after 6 years of follow-up (61). A direct comparison of both procedures was published in 2012 (39). This was a randomized, evaluator-blind study with 198 PD patients followed up for at least 36 months, which concluded that the primary outcome, OFF period motor improvement (including subscales for each motor sign), was significantly improved, but the improvements were similar, stable over time, and with parallel trends for both targets. The scores for complications of levodopa therapy (UPDRS IV), including dyskinesia, as well as the amount of ON period time without troublesome LID were significantly improved for both groups over 36 months, with non-significant, but greater decreases in levodopa dosages in the STN group. Finally, one recent doubleblind study of $128 \mathrm{PD}$ patients randomized for either form of treatment, showed that patients who underwent STN DBS had larger improvements in OFF period mean UPDRS motor score, mean change in ADLs scores and mean reduction in medication after surgery. OFF dystonia scores were similarly improved as well as the time in ON phase without dyskinesia. The scores of the dyskinesia rating scales were significantly better 12 months after surgery for those who underwent GPi DBS. This difference probably occurred because the authors assessed patients after 12 months with the same dose of levodopa used at baseline, however in daily life, they may use lower doses, leading to less LID (40).

\section{PRACTICAL ISSUES; SELECTION OF THE SURGICAL TARGET, TECHNIQUE, AND PROGRAMING}

Table 1 shows a summary of points that need to be considered when indicating these DBS techniques.

Numerous studies have demonstrated the effectiveness of STN DBS in controlling the appendicular motor signs of PD, however, this procedure is not considered to have as much of a direct effect on the intensity of LID. The anti-dyskinetic effect of STN DBS have been hypothesized to be related to allowing reduction of dopaminergic drug dosages, with consequent improvement in side effects, including LID. The persistence or worsening of LID after STN DBS is common and is, in fact, indicative of the necessity to reduce the dose of levodopa (62). Therefore, the si ne qua non-condition for reduction of LID when STN DBS is considered, is its capacity to enable a reduction of levodopa dosage. If, however, an adequate response of motor symptoms does not occur post-operatively, dyskinesia will remain unchanged. Of importance, STN stimulation not uncommonly induces contralateral dyskinesia, which may be persistent, and in some cases lead to the implantation of rescue GPi leads.

On the other hand, GPi DBS seems to have a direct effect on the reduction of dyskinesia. Patients undergoing this procedure typically cannot tolerate significantly lower doses of levodopa after surgery, and still appreciate a marked reduction of dyskinesia. Simplistically, patients who experience a good response of their PD symptoms with levodopa, but whose primary and most significant source of disability are dyskinesia may benefit from GPi DBS (51). In other words, GPi DBS can be especially valuable for cases in which LID are a dose-limiting factor for either maintaining or introducing higher but necessary levels of dopaminergic therapy. In addition, levodopa may have a synergistic effect on GPi DBS, which is not seen after STN stimulation. Burchiel et al., for instance, in a randomized, double-blind study, comparing the effects of STN and GPi DBS, showed that, in combination with levodopa, UPDRS motor scores were significantly more improved for patients who underwent the pallidal procedure. This combination was also more clinically significant for axial symptoms, which are traditionally considered refractory to either form of treatment alone (63). Another more recent meta-regression of 
long-term studies of cases who underwent these procedures confirmed that GPi DBS in combination with levodopa was correlated with better scores for postural instability and gait disorder than STN stimulation plus levodopa (64).

Selection of either target may also be influenced by the fact that medications used for the treatment of PD are useful not only for motor, but also for psychiatric, cognitive, sleep, and other non-motor aspects of the disease, therefore, withdrawal or dose reduction may not be a desired goal (65). Selection of the target should be based on the patient's most disabling symptoms, response, and side effects related to levodopa, and the ultimate goals of therapy (66). If LID are a patient's most disabling symptom, especially if they require more immediate improvement due to its severity and potential morbidity, then GPi DBS should be considered with the knowledge that regardless of changes in medication therapy after surgery there is a high likelihood that dyskinesia will improve. On the other hand, patients undergoing STN DBS must hope for a sufficiently good response after surgery that will allow medications to be sufficiently reduced. If change in parkinsonian motor symptoms after STN DBS are insufficient to guarantee reduction of levodopa dosage, or if its reduction worsen or induces non-motor symptoms, the intervention for dyskinesia may be "unfruitful" (1).

In the case of a patient in whom, in addition to motor signs of parkinsonism, medication side effects other than dyskinesia are a primary source of disability (i.e., psychosis, behavioral changes, etc.), STN DBS may be more desirable.

In general, when the presence of LID is the main problem and indication for surgery, there are no formal differences in the procedures when compared to situations when the chief complaint is another motor feature of the disease. However, a few minor variables exist. Implantation of leads is typically performed while patients are in the OFF condition to avoid disabling dyskinesia, leading to motion artifacts during pre operative imaging and to better microelectrode recording during the intraoperative procedure (67). Other variations are used because of possible differential anti-dyskinetic effects of stimulation at different sites within the GPi as stimulation of two different sites within the nucleus induce different effects on dyskinesia and response to dopaminergic treatment. Studies have shown that stimulation of the most dorsal aspects of the GPi in the OFF period usually leads to improvement of the cardinal signs, especially bradykinesia, while inducing dyskinesia, mimicking the action of levodopa. When deeper (ventral) sites within the nucleus were stimulated, signs worsened. In the ON period, stimulation of the ventral GPi reduced dyskinesia but may have worsened bradykinesia. Stimulation of the intermediate area seems to provide a balance between these two extremes. It is unclear whether these findings have a practical significance, but their existence should be kept in mind during surgical planning, positioning of the lead within the GPi, and during programing sessions $(56,57)$.

\section{Post-operative programing: GPi DBS}

As a rule, the evaluation of stimulation-related beneficial effects is typically less reliable during the first weeks after electrode implantation, due to the lesion effect of the procedure. Therefore, the initial programing should be performed after at least 2 weeks of surgery. At this time, the patient should be in the OFF medication condition, after $12 \mathrm{~h}$ of dopaminergic drug withdrawal. The first step should focus on achieving the best improvement of the cardinal signs of parkinsonism. The second phase should address the patient during the ON period, under the effect of levodopa, with particular awareness for LID. Therefore, the goal of programing should be attempting to achieve a good relief of PD symptoms in the OFF condition, not associated with the occurrence of dyskinesia in the ON period, and with the highest threshold for side effects of stimulation. This procedure should be performed for all four contacts separately, defining a hierarchy for therapeutic window (68).

In patients whose primary complaint is LID, an additional programing session can be performed in a full $\mathrm{ON}$ condition to confirm the adequate beneficial effect of stimulation, but is usually only indicated if there are difficulties suppressing dyskinesia. Special attention must be directed to ensure that beneficial medication effects are not antagonized by stimulation, as well as the OFF medication symptoms are not exacerbated, since different regions within the GPi may have opposite effects on dyskinesia and on the cardinal signs of parkinsonism, when stimulated. Fortunately, the detrimental effects of stimulation on parkinsonism and the response to levodopa have higher thresholds than the beneficial effects on dyskinesia. As ventral GPi areas may provide good relief of dyskinesia at the expense of loss of beneficial effect of levodopa, a better stimulation response can be detected by using more central contacts, which usually provide good relief of dyskinesia as well as tremor, rigidity, and bradykinesia $(56,69)$. It is important to point out that many experts have been unable to replicate the differential effects of programing different contacts in the GPi, and that in general the GPi has been found to be a much easier target to optimize. The GPi target also allows for more flexibility that the STN target, as was recently shown by Weaver et al. in VA study 36 months outcomes $(39,70)$.

\section{Post-operative programing: STN DBS}

As STN DBS ideally mimics the motor effects of levodopa in many aspects, the main objective of initial programing in cases of dyskinesia relies on providing a significant improvement of the motor signs of parkinsonism and a concomitant decrease in levodopa dosage, which, on average, reaches a 50\% reduction (41). Therefore, as in the case of GPi DBS, the first programing session should preferentially be performed in patients during the OFF period, holding all medications for PD for $12 \mathrm{~h}$. In fact, most experts that program STN and GPi DBS have patients report to the clinic in an OFF medication condition, which provides a nearly optimal programing scenario (no bias of medications). This is generally enough for most patients, however some patients may require longer OFF periods. In difficult cases, after programing for reduction of bradykinesia, tremor, and, especially, rigidity, patients should take their regular doses of levodopa and, in the ON state, be assessed for adverse effects with the combination of stimulation and medications, particularly dyskinesia. The patient should be seen during this first session at the peak effect of levodopa, and ideally should have access to expert programing for the next few days, as dyskinesia may appear after a latency period of up to several hours $(71,72)$. During the first few weeks and months 
after surgery, as stimulation is adjusted to provide the best relief of parkinsonian symptoms, medication doses can be slowly titrated downward, and LID tends to improve or resolve. Moreover, dyskinesia has been hypothesized to improve with chronic continuous stimulation due to plastic changes as a direct effect of stimulation, leading to desensitization of the neuronal circuitry underlying to LID. Persistent dyskinesia is generally treated by further reduction of medication (71).

In some instances, especially during the first few weeks after DBS implantation, dyskinesia may be exacerbated and, in fact, the induction of these involuntary movements in the short term predicts a favorable long-term outcome (51). Thus, the particular electrode that induces dyskinesia is usually the most effective contact for long-term therapy. In these cases, if reducing levodopa leads to worsening of PD symptoms, medication doses should be kept at the lowest adequate therapeutic level, and stimulation amplitudes or other parameters should be reduced. Over time, the threshold for induction of dyskinesia typically increases, and amplitude can be gradually increased (73). Finally, if stimulation using the most effective contact precipitates dyskinesia that cannot be controlled except by unacceptable reduction of stimulation intensity, programing the system to use a more proximal contact in a monopolar configuration, or reprograming to a bipolar configuration may be necessary. Addition of a contact dorsal to the STN (perhaps in the zona incerta) may also provide better control of dyskinesia (71).

\section{CONCLUSION}

Although STN and GPi procedures have different mechanisms of action, both are effective treatments strategies to control LID. GPi interventions may have a more immediate effect, independent of reduction of levodopa daily dosage. On the other hand, several centers tend to adopt STN DBS as this procedure also brings marginally better improvements in OFF period motor scores than GPI DBS, as indicated by a recent randomized controlled trial (40). Overall, selection of the surgical target should be based on each patient's most disabling symptoms, medication response and regimen, and goals of therapeutic intervention. Currently, the literature is almost entirely focused on results that analyze a combination of the best possible results in regards to global improvements, therefore the ideal stimulation parameters specific for the control of LID are unknown. Also, the anti-dyskinetic effects of additional or combined targets, such as external and internal pallidal stimulation, and the use of adaptive DBS remain largely unexplored.

\section{REFERENCES}

1. Follett KA. Comparison of pallidal and subthalamic deep brain stimulation for the treatment of levodopa-induced dyskinesia. Neurosurg Focus (2004) 17:E3. doi:10.3171/foc.2004.17.1.3

2. Guridi J, Lozano AM. A brief history of pallidotomy. Neurosurgery (1997) 41:1169-80. doi:10.1097/00006123-199711000-00029

3. Cooper IS. Surgical alleviation of Parkinsonism; effects of occlusion of the anterior choroidal artery. J Am Geriatr Soc (1954) 2:691-718.

4. Rand RW, Stern WE, Orr JK. Parkinsonism; early results of occlusion of the anterior choroidal artery. Calif Med (1954) 81:276-8.

5. Gillingham J. Forty-five years of stereotactic surgery for Parkinson's disease: a review. Stereotact Funct Neurosurg (2000) 74:95-8. doi:10.1159/000056469
6. Okun MS, Vitek JL. Lesion therapy for Parkinson's disease and other movement disorders: update and controversies. Mov Disord (2004) 19:375-89. doi: $10.1002 / \mathrm{mds} .20037$

7. Speelman JD, Bosch DA. Resurgence of functional neurosurgery for Parkinson's disease: a historical perspective. Mov Disord (1998) 13:582-8. doi:10.1002/mds. 870130336

8. Lang AE, Lozano AM. Parkinson's disease. Second of two parts. N Engl J Med (1998) 339:1130-43. doi:10.1056/NEJM199810153391607

9. Tasker RR, Siqueira J, Hawrylyshyn P, Organ LW. What happened to VIM thalamotomy for Parkinson's disease? Appl Neurophysiol (1983) 46:68-83.

10. Svennilson E, Torvik A, Lowe R, Leksell L. Treatment of parkinsonism by stereotatic thermolesions in the pallidal region. A clinical evaluation of 81 cases. Acta Psychiatr Scand (1960) 35:358-77. doi:10.1111/j.1600-0447.1960. tb07606.x

11. Laitinen LV, Bergenheim AT, Hariz MI. Leksell's posteroventral pallidotomy in the treatment of Parkinson's disease. J Neurosurg (1992) 76:53-61. doi:10.3171/ jns.1992.76.1.0053

12. Bergman H, Wichmann T, DeLong MR. Reversal of experimental parkinsonism by lesions of the subthalamic nucleus. Science (1990) 249:1436-8. doi: $10.1126 /$ science. 2402638

13. Aziz TZ, Peggs D, Agarwal E, Sambrook MA, Crossman AR. Subthalamic nucleotomy alleviates parkinsonism in the 1-methyl-4-phenyl-1,2,3,6tetrahydropyridine (MPTP)-exposed primate. Br J Neurosurg (1992) 6:575-82. doi:10.3109/02688699209002375

14. Hamada I, DeLong MR. Excitotoxic acid lesions of the primate subthalamic nucleus result in reduced pallidal neuronal activity during active holding. $J$ Neurophysiol (1992) 68:1859-66.

15. Lozano AM, Lang AE. Pallidotomy for Parkinson's disease. Adv Neurol (2001) 86:413-20.

16. Lang AE, Lozano AM, Montgomery E, Duff J, Tasker R, Hutchinson W. Posteroventral medial pallidotomy in advanced Parkinson's disease. N Engl J Med (1997) 337:1036-42. doi:10.1056/NEJM199710093371503

17. Fine J, Duff J, Chen R, Chir B, Hutchison W, Lozano AM, et al. Long-term follow-up of unilateral pallidotomy in advanced Parkinson's disease. $N$ Engl J Med (2000) 342:1708-14. doi:10.1056/NEJM200006083422304

18. Samuel M, Caputo E, Brooks DJ, Schrag A, Scaravilli T, Branston NM, et al. A study of medial pallidotomy for Parkinson's disease: clinical outcome, MRI location and complications. Brain (1998) 121:59-75. doi:10.1093/brain/121.1.59

19. Vitek JL, Bakay RA, Freeman A, Evatt M, Green J, McDonald W, et al. Randomized trial of pallidotomy versus medical therapy for Parkinson's disease. Ann Neurol (2003) 53:558-69. doi:10.1002/ana.10517

20. Kleiner-Fisman G, Lozano A, Moro E, Poon YY, Lang AE. Long-term effect of unilateral pallidotomy on levodopa-induced dyskinesia. Mov Disord (2010) 25:1496-8. doi:10.1002/mds.23155

21. Hariz MI, Bergenheim AT. A 10-year follow-up review of patients who underwent Leksell's posteroventral pallidotomy for Parkinson disease. J Neurosurg (2001) 94:552-8. doi:10.3171/jns.2001.94.4.0552

22. Goodman SH, Wilkinson S, Overman J, Koller WC, Tröster A, Pahwa R, et al. Lesion volume and clinical outcome in stereotactic pallidotomy and thalamotomy. Stereotact Funct Neurosurg (1998) 71:164-72. doi:10.1159/000029660

23. Gross RE, Lombardi WJ, Lang AE, Duff J, Hutchison WD, Saint-Cyr JA, et al. Relationship of lesion location to clinical outcome following microelectrodeguided pallidotomy for Parkinson's disease. Brain (1999) 122:405-16. doi:10. 1093/brain/122.3.405

24. Pincus MM. Beneficial effect of bilateral pallidotomy on gait is unproven. Arch Neurol (2000) 57:1231-2. doi:10.1001/archneur.57.8.1231

25. Siegel KL, Metman LV. Effects of bilateral posteroventral pallidotomy on gait of subjects with Parkinson disease. Arch Neurol (2000) 57:198-204. doi:10.1001/ archneur.57.2.198

26. Intemann PM, Masterman D, Subramanian I, DeSalles A, Behnke E, Frysinger R, et al. Staged bilateral pallidotomy for treatment of Parkinson disease. J Neurosurg (2001) 94:437-44. doi:10.3171/jns.2001.94.3.0437

27. Favre J, Burchiel KJ, Taha JM, Hammerstad J. Outcome of unilateral and bilateral pallidotomy for Parkinson's disease: patient assessment. Neurosurgery (2000) 46:344-53. doi:10.1097/00006123-200002000-00017

28. Counihan TJ, Shinobu LA, Eskandar EN, Cosgrove GR, Penney JB Jr. Outcomes following staged bilateral pallidotomy in advanced Parkinson's disease. Neurology (2001) 56:799-802. doi:10.1212/WNL.56.6.799 
29. Parkin SG, Gregory RP, Scott R, Bain P, Silburn P, Hall B, et al. Unilateral and bilateral pallidotomy for idiopathic Parkinson's disease: a case series of 115 patients. Mov Disord (2002) 17:682-92. doi:10.1002/mds.10186

30. Kumar R, Lozano AM, Montgomery E, Lang AE. Pallidotomy and deep brain stimulation of the pallidum and subthalamic nucleus in advanced Parkinson's disease. Mov Disord (1998) 13:73-82.

31. Esselink RA, de Bie RM, de Haan RJ, Lenders MW, Nijssen PC, Staal MJ, et al. Unilateral pallidotomy versus bilateral subthalamic nucleus stimulation in PD: a randomized trial. Neurology (2004) 62:201-7. doi:10.1212/01.WNL. 0000103235.12621.C3

32. Esselink RA, de Bie RM, de Haan RJ, Lenders MW, Nijssen PC, van Laar T, et al. Long-term superiority of subthalamic nucleus stimulation over pallidotomy in Parkinson disease. Neurology (2009) 73:151-3. doi:10.1212/WNL. 0b013e3181ad536c

33. Lozano AM, Lang AE, Galvez-Jimenez N, Miyasaki J, Duff J, Hutchinson WD, et al. Effect of GPi pallidotomy on motor function in Parkinson's disease. Lancet (1995) 346:1383-7. doi:10.1016/S0140-6736(95)92404-3

34. Kumar R, Lang AE, Rodriguez-Oroz MC, Lozano AM, Limousin P, Pollak P, et al. Deep brain stimulation of the globus pallidus pars interna in advanced Parkinson's disease. Neurology (2000) 55:S34-9.

35. Deep-Brain Stimulation for Parkinson's Disease Study Group X. Deep-brain stimulation of the subthalamic nucleus or the pars interna of the globus pallidus in Parkinson's disease. N Engl J Med (2001) 345:956-63. doi:10.1056/ NEJMoa000827

36. Rodriguez-Oroz MC, Obeso JA, Lang AE, Houeto JL, Pollak P, Rehncrona S, et al. Bilateral deep brain stimulation in Parkinson's disease: a multicentre study with 4 years follow-up. Brain (2005) 128(Pt 10):2240-9. doi:10.1093/brain/ awh571

37. Krack P, Batir A, Van Blercom N, Chabardes S, Fraix V, Ardouin C, et al. Five-year follow-up of bilateral stimulation of the subthalamic nucleus in advanced Parkinson's disease. N Engl J Med (2003) 349:1925-34. doi:10.1056/ NEJMoa035275

38. Follett KA, Weaver FM, Stern M, Hur K, Harris CL, Luo P, et al. Pallidal versus subthalamic deep-brain stimulation for Parkinson's disease. $N$ Engl J Med (2010) 362:2077-91. doi:10.1056/NEJMoa0907083

39. Weaver FM, Follett KA, Stern M, Luo P, Harris CL, Hur K, et al. Randomized trial of deep brain stimulation for Parkinson disease: thirty-six-month outcomes. Neurology (2012) 79:55-65. doi:10.1212/WNL.0b013e31825dcdc1

40. Odekerken VJ, van Laar T, Staal MJ, Mosch A, Hoffmann CF, Nijssen PC, et al. Subthalamic nucleus versus globus pallidus bilateral deep brain stimulation for advanced Parkinson's disease (NSTAPS study): a randomised controlled trial. Lancet Neurol (2013) 12:37-44. doi:10.1016/S1474-4422(12) 70264-8

41. Moro E, Scerrati M, Romito LM, Roselli R, Tonali P, Albanese A. Chronic subthalamic nucleus stimulation reduces medication requirements in Parkinson's disease. Neurology (1999) 53:85-90. doi:10.1212/WNL.53.1.85

42. Hooper AK, Okun MS, Foote KD, Fernandez HH, Jacobson C, Zeilman P, et al. Clinical cases where lesion therapy was chosen over deep brain stimulation. Stereotact Funct Neurosurg (2008) 86:147-52. doi:10.1159/000120426

43. Munhoz RP, Teive HA, Francisco AN, Raskin S, Rogaeva E. Unilateral pallidotomy in a patient with parkinsonism and G2019S LRRK2 mutation. Mov Disord (2009) 24:791-2. doi:10.1002/mds.21818

44. Terzic D, Abosch A. Update on deep brain stimulation for Parkinson's disease. J Neurosurg Sci (2012) 56:267-77.

45. Siegfried J, Lippitz B. Bilateral chronic electrostimulation of ventroposterolateral pallidum: a new therapeutic approach for alleviating all parkinsonian symptoms. Neurosurgery (1994) 35:1126-9. doi:10.1227/00006123-199412000-00016

46. Ghika J, Villemure JG, Fankhauser H, Favre J, Assal G, Ghika-Schmid F. Efficiency and safety of bilateral contemporaneous pallidal stimulation (deep brain stimulation) in levodopa-responsive patients with Parkinson's disease with severe motor fluctuations: a 2-year follow-up review. J Neurosurg (1998) 89:713-8. doi:10.3171/jns.1998.89.5.0713

47. Volkmann J, Allert N, Voges J, Sturm V, Schnitzler A, Freund HJ. Long-term results of bilateral pallidal stimulation in Parkinson's disease. Ann Neurol (2004) 55:871-5. doi:10.1002/ana.20091

48. Limousin P, Krack P, Pollak P, Benazzouz A, Ardouin C, Hoffmann D, et al. Electrical stimulation of the subthalamic nucleus in advanced Parkinson's disease. N Engl J Med (1998) 339:1105-11. doi:10.1056/NEJM199810153391603
49. Krack P, Pollak P, Limousin P, Benazzouz A, Deuschl G, Benabid AL. From off-period dystonia to peak-dose chorea. The clinical spectrum of varying subthalamic nucleus activity. Brain (1999) 122:1133-46. doi:10.1093/brain/122. 6.1133

50. Krack P, Limousin P, Benabid AL, Pollak P. Chronic stimulation of subthalamic nucleus improves levodopa-induced dyskinesia in Parkinson's disease. Lancet (1997) 350:1676. doi:10.1016/S0140-6736(05)64273-0

51. Oyama G, Foote KD, Jacobson CE IV, Velez-Lago F, Go C, Limotai N, et al. GPi and STN deep brain stimulation can suppress dyskinesia in Parkinson's disease. Parkinsonism Relat Disord (2012) 18:814-8. doi:10.1016/j.parkreldis.2012.03. 022

52. Schüpbach WM, Chastan N, Welter ML, Houeto JL, Mesnage V, Bonnet AM, et al. Stimulation of the subthalamic nucleus in Parkinson's disease: a 5 year follow up. J Neurol Neurosurg Psychiatry (2005) 76:1640-4. doi:10.1136/jnnp. 2005.063206

53. Kleiner-Fisman G, Herzog J, Fisman DN, Tamma F, Lyons KE, Pahwa R, et al. Subthalamic nucleus deep brain stimulation: summary and meta-analysis of outcomes. Mov Disord (2006) 21(Suppl 14):S290-304. doi:10.1002/mds. 20962

54. Krack P, Pollak P, Limousin P, Hoffmann D, Benazzouz A, Le Bas JF, et al. Opposite motor effects of pallidal stimulation in Parkinson's disease. Ann Neurol (1998) 43:180-92. doi:10.1002/ana.410430208

55. Wu YR, Levy R, Ashby P, Tasker RR, Dostrovsky JO. Does stimulation of the GPi control dyskinesia by activating inhibitory axons? Mov Disord (2001) 16:208-16. doi: $10.1002 / \mathrm{mds} .1046$

56. Bejjani B, Damier P, Arnulf I, Bonnet AM, Vidailhet M, Dormont D, et al. Pallidal stimulation for Parkinson's disease. Two targets? Neurology (1997) 49:1564-9. doi:10.1212/WNL.49.6.1564

57. Krack P, Pollak P, Limousin P, Hoffmann D, Xie J, Benazzouz A, et al. Subthalamic nucleus or internal pallidal stimulation in young onset Parkinson's disease. Brain (1998) 121:451-7. doi:10.1093/brain/121.3.451

58. Katayama Y, Oshima H, Kano T, Kobayashi K, Fukaya C, Yamamoto T. Direct effect of subthalamic nucleus stimulation on levodopa-induced peak-dose dyskinesia in patients with Parkinson's disease. Stereotact Funct Neurosurg (2006) 84:176-9. doi:10.1159/000094957

59. Plaha P, Ben-Shlomo Y, Patel NK, Gill SS. Stimulation of the caudal zona incerta is superior to stimulation of the subthalamic nucleus in improving contralateral parkinsonism. Brain (2006) 129:1732-47. doi:10.1093/brain/awl127

60. Saint-Cyr JA, Hoque T, Pereira LC, Dostrovsky JO, Hutchison WD, Mikulis DJ, et al. Localization of clinically effective stimulating electrodes in the human subthalamic nucleus on magnetic resonance imaging. J Neurosurg (2002) 97:1152-66. doi:10.3171/jns.2002.97.5.1152

61. Moro E, Lozano AM, Pollak P, Agid Y, Rehncrona S, Volkmann J, et al. Longterm results of a multicenter study on subthalamic and pallidal stimulation in Parkinson's disease. Mov Disord (2010) 25:578-86. doi:10.1002/mds.22735

62. Deuschl G, Paschen S, Witt K. Clinical outcome of deep brain stimulation for Parkinson's disease. Handb Clin Neurol (2013) 116C:107-28. doi:10.1016/B9780-444-53497-2.00010-3

63. Burchiel KJ, Anderson VC, Favre J, Hammerstad JP. Comparison of pallidal and subthalamic nucleus deep brain stimulation for advanced Parkinson's disease: results of a randomized, blinded pilot study. Neurosurgery (1999) 45:1375-82. doi:10.1097/00006123-199912000-00024

64. St George RJ, Nutt JG, Burchiel KJ, Horak FB. A meta-regression of the longterm effects of deep brain stimulation on balance and gait in PD. Neurology (2010) 75:1292-9. doi:10.1212/WNL.0b013e3181f61329

65. Munhoz RP, Werneck LC, Teive HA. The differential diagnoses of parkinsonism: findings from a cohort of 1528 patients and a 10 years comparison in tertiary movement disorders clinics. Clin Neurol Neurosurg (2010) 112:431-5. doi:10.1016/j.clineuro.2010.03.003

66. Okun MS, Foote KD. Parkinson's disease DBS: what, when, who and why? The time has come to tailor DBS targets. Expert Rev Neurother (2010) 10:1847-57. doi:10.1586/ern.10.156

67. Bronstein JM, Tagliati M, Alterman RL, Lozano AM, Volkmann J, Stefani A, et al. Deep brain stimulation for Parkinson disease: an expert consensus and review of key issues. Arch Neurol (2011) 68:165. doi:10.1001/archneurol.2010.260

68. Kumar R. Methods for programming and patient management with deep brain stimulation of the globus pallidus for the treatment of advanced Parkinson's disease and dystonia. Mov Disord (2002) 17:S198-207. doi:10.1002/mds.10164 
69. Volkmann J, Herzog J, Kopper F, Deuschl G. Introduction to the programming of deep brain stimulators. Mov Disord (2002) 17:S181-7. doi:10.1002/mds. 10162

70. Tagliati M. Turning tables: should GPi become the preferred DBS target for Parkinson disease? Neurology (2012) 79:19-20. doi:10.1212/WNL. 0b013e31825dce96

71. Krack P, Fraix V, Mendes A, Benabid AL, Pollak P. Postoperative management of subthalamic nucleus stimulation for Parkinson's disease. Mov Disord (2002) 17:S188-97. doi:10.1002/mds.10163

72. Mazzone P. Deep brain stimulation in Parkinson's disease: bilateral implantation of globus pallidus and subthalamic nucleus. J Neurosurg Sci (2003) 47: 47-51.

73. Deuschl G, Fogel W, Hahne M, Kupsch A, Müller D, Oechsner M, et al. Deep-brain stimulation for Parkinson's disease. J Neurol (2002) 249:III/36-9. doi:10.1007/s00415-002-1308-x
Conflict of Interest Statement: The authors declare that the research was conducted in the absence of any commercial or financial relationships that could be construed as a potential conflict of interest.

Received: 19 December 2013; accepted: 16 April 2014; published online: 29 April 2014. Citation: Munhoz RP, Cerasa A and Okun MS (2014) Surgical treatment of dyskinesia in Parkinson's disease. Front. Neurol. 5:65. doi: 10.3389/fneur.2014.00065

This article was submitted to Movement Disorders, a section of the journal Frontiers in Neurology.

Copyright (C) 2014 Munhoz, Cerasa and Okun. This is an open-access article distributed under the terms of the Creative Commons Attribution License (CC BY). The use, distribution or reproduction in other forums is permitted, provided the original author(s) or licensor are credited and that the original publication in this journal is cited, in accordance with accepted academic practice. No use, distribution or reproduction is permitted which does not comply with these terms. 